Revista Eletrônica de Ciência Administrativa (RECADM) - ISSN 1677-7387

Faculdade Cenecista de Campo Largo - Coordenação do Curso de Administração

v. 3, n. 2, nov./2004 - http://revistas.facecla.com.br/index.php/recadm/

\title{
REDE DE EMPRESAS : UMA EXPERIÊNCIA DO CONSÓRCIO DE EMPRESAS DE BASE TECNOLÓGICA
}

\author{
Waleska Silveira Lira - Doutoranda em Engenharia de Produção -UFPB \\ Email - waleska.silveira@terra.com.br. \\ Dr .Geraldo Maciel de Araújo.- Programa de Doutorado em Engenharia da Produção \\ UFPB - Campus I. \\ Dra. Maria de Lourdes Barreto Gomes - Programa de Doutorado em Engenharia da \\ Produção-UFPB - Campus I.
}

\section{RESUMO}

As redes de empresas constituem uma nova forma de competir no mercado como também uma estratégia de desenvolvimento regional, através da criação de consórcios e formação de alianças estratégicas.Este artigo faz uma abordagem de redes de empresas, de alianças estratégicas através de consórcios de exportação e da experiência do Estado da Paraíba através da formação do consórcio de exportação de softwares - o Consórcio PBTECH, além de fazer uma análise da visão de três empresas de base tecnológica na participação do Consórcio de Exportação da Paraíba e suas expectativas para o futuro em termos de crescimento empresarial. O presente estudo adotou com procedimento metodológico uma pesquisa bibliográfica e um estudo de multi-caso de cunho descritivo e exploratório. Através da pesquisa, pode-se concluir que a formação de redes de empresas através da utilização das estratégias de consórcio de exportação apresenta vantagem competitiva, por existir na região empresas de base tecnológica como núcleo central da rede, e uma forte tendência de crescimento a partir da capacitação tecnológica preexistente na cidade de Campina Grande. O principal objetivo das empresas objeto de estudo, em participar do consórcio PBTECH foi à ampliação do mercado, a redução dos custos, a formação de um grupo de empresários e agentes multiplicadores para disseminação das tecnologias e a mudança de atitude frente à internacionalização. A integração das redes de empresas deixou de ser uma função meio para ser uma função fim, por necessidade de manter-se competitiva no mercado global na qual a sociedade da informação está inserida.

Palavras-Chaves : Redes de Empresas, Consórcios, Estratégia, Desenvolvimento Regional. 
Revista Eletrônica de Ciência Administrativa (RECADM) - ISSN 1677-7387

Faculdade Cenecista de Campo Largo - Coordenação do Curso de Administração v. 3, n. 2, nov./2004 - http://revistas.facecla.com.br/index.php/recadm/

\begin{abstract}
Industrial networks constitute a new form to compete in the market as well as a strategy of regional development, through the creation of consortium of company and formation strategic alliances. This article makes a outline of the industrial networks, strategically alliances through consortium of exportation and the experience of the State of the Paraíba through the formation of the exportation consortium of software - Consórcio PBTECH, beside this work making an analysis of the vision of three companies of technological base in the participation of the Consórcio de Exportação da Paraíba and its expectations for the future in terms of enterprise growth. In this study it was adopted as a methodology a bibliographical research and a descriptive and investigative multi-case study. Through the research, it can be concluded that the formation of the industrial networks through the use of the strategy of exportation consortium presents competitive advantage, for existing in the region companies of technological base as central nucleus of the net, and a strong tendency of growth from the preexisting technological qualification in the city of Campina Grande. The main objective of the studied companies, in participating of the Consórcio PBTECH was to expand the market, the reduce the costs, the formation of a entrepreneurs group and multiplying agents for diffusion of technologies and the change of attitude in relation to the internationalization. The integration of the industrial networks is not only the way but also the final function, mainly for the need to remain competitive in the global market in which the society of the information is inserted.
\end{abstract}

Word-Key: Industrial networks, Consortium, Strategy, Regional Development. 
Revista Eletrônica de Ciência Administrativa (RECADM) - ISSN 1677-7387

Faculdade Cenecista de Campo Largo - Coordenação do Curso de Administração

v. 3, n. 2, nov./2004 - http://revistas.facecla.com.br/index.php/recadm/

\section{1- INTRODUÇÃO}

A agressividade e agilidade do mercado externo e globalizado constituem exigências muitas vezes difíceis de serem atendidas pelas micros e pequenas empresas. A internacionalização da produção e das operações financeiras, com a liberação do comércio e a desregulamentação de fronteiras, são alguns dos aspectos que vêm impulsionando este fenômeno e mudando as características de penetração e aceitação de mercado em todo o mundo.

Com o processo de globalização se torna mais difícil ser líder no mercado sem que a região em que a empresa se encontra não tenha destaque nacional ou internacional. Sobre esta realidade, está surgindo o conceito de redes de empresas, que projeta suas atividades para o mercado internacional de maneira integrada, com base em uma estratégia comum.

Um dos objetivos da rede de empresa é o desenvolvimento local através de consórcios e formação de alianças estratégicas. Estas alianças envolvem acordos formais e informais entre empresas que permitem um intercâmbio de informação e uma aglutinação de competências.

No Brasil, as micros e pequenas empresas carecem de capital, têm dificuldade de acesso a novos mercados, e grande parte de seus proprietários não estão preparados para enfrentar os novos desafios inerentes à abertura de mercados e a evolução tecnológica.

Uma experiência utilizadas pelas micros e pequenas empresas italianas para enfrentar a crise na década de 80 foram à união em forma de consórcios para enfrentar os desafios e sair da crise na época.

Os consórcios são uma forma viável para aplicar estratégias conjuntas e visualizar resultados em curto prazo, aumentando a colaboração entre empresas e auxiliando no desenvolvimento regional através da utilização inovações tecnológicas.

Este artigo focaliza o uso dessas redes para obtenção de eficiência e ampliação de mercado, em virtude da aglomeração espacial de atividades complementares do ponto de vista tecnológico, especificamente distritos industriais com setores de alta tecnologia como por exemplo, o pólo tecnológico de Campina Grande que podem ser a base para um 
Revista Eletrônica de Ciência Administrativa (RECADM) - ISSN 1677-7387

Faculdade Cenecista de Campo Largo - Coordenação do Curso de Administração v. 3, n. 2, nov./2004 - http://revistas.facecla.com.br/index.php/recadm/

crescimento capaz de aumentar a demanda por mão-de-obra , o nível de salários e o padrão de vida da região.

O artigo tem o objetivo de analisar a experiência da formação de consórcios de empresa de base tecnológica no estado da Paraíba, através de um procedimento metodológico de pesquisa de multi-caso, como o intuito de saber se a formação de redes de empresas através da utilização das estratégias de consórcio de exportação apresenta vantagens competitivas?

\section{2- REDES DE EMPRESAS}

Os processos e as funções dominantes na era da informação estão cada vez mais organizados em rede. Segundo Castells (2000,p.497)

\footnotetext{
"redes constituem uma nova morfologia social de nossa sociedade, e a difusão da lógica das redes modifica de forma substancial a operação e os resultados dos processos produtivos e de experiência, poder e cultura’”.
}

A rede se caracteriza por ser uma estrutura aberta capaz de se expandir de forma ilimitada, integrando novos nós desde que consigam comunicar-se entre si e dentro da rede. Sua estrutura social é um sistema dinâmico e suscetível de inovação.

O conceito de redes de empresas refere-se a arranjos interorganizacionais baseado em vínculos sistemáticos, muitas vezes de caráter cooperativo entre empresas formalmente independentes, que dão origem a uma forma particular de coordenação das atividades econômicas. (Hasenclever at al: 2002,p.347).

A formação das redes de negócios para as micros e pequenas empresas é uma forma de adquirir vantagens competitiva, melhores condições de sobrevivência e contribuir para o desenvolvimento regional.

As redes sofrem influências de um conjunto de variações e aplicações que dependem do tipo de ambiente onde estão inseridas, das características regional, das políticas governamentais existentes, cultura do povo, da tecnologia disponível e outros fatores.

As redes de micro e pequenas empresas competem internacionalmente e formam a cadeia de valor inteira dentro de um processo onde são chamadas de redes flexíveis. Na 
Revista Eletrônica de Ciência Administrativa (RECADM) - ISSN 1677-7387

Faculdade Cenecista de Campo Largo - Coordenação do Curso de Administração

v. 3, n. 2, nov./2004 - http://revistas.facecla.com.br/index.php/recadm/

visão de Perrow (1992; apud Zaleski 1999) alguns fatores beneficiam a formação de redes para o desenvolvimento regional através das micros e pequenas empresas:

1. Maior dispersão de poder entre as várias empresas da região;

2. Flexibilização da hierarquia, decorrente do menor número de níveis verticais existentes nas pequenas empresas;

3. Mudança na distribuição da riqueza e nos padrões de consumo;

4. O progresso resultante das redes de pequenas empresas é mais equilibrado do que aquele produzido por grandes empresas, que acabam investindo fora da região;

5. Incentivo ao desenvolvimento de uma estrutura de apoio do governo regional oferecendo amplos serviços sociais que apoiam a formação de redes.

\section{1.- Tipologia de Redes de Empresas}

Existe uma vasta classificação, que vem se dedicando a um construto de tipos de redes de empresas. As formações recentes de redes de empresas podem ser consideradas como formas especiais de alianças estratégicas.

Para Casarotto (1998) existem dois tipos de redes, a forma topdown, onde a pequena empresa pode tornar-se fornecedora da empresa mãe, tendo pouca ou nenhuma flexibilidade e é altamente dependente desta, e, a outra, em forma de Consórcio que atua de forma flexível onde às empresas unem-se para administrar e planejar estratégias de negócios.

Neste segundo modelo, a necessidade da formação de um consórcio pode ser executada ao longo dos anos da atuação de empresas do mesmo setor de uma determinada região, onde a questão cultural levará incondicionalmente a esta formação. Já em outras situações, a formação dos consórcios poderá ser orientada por instituições locais ou pela união das empresas em torno de um objetivo comum.

O autor ressalta que uma região deve apresentar então os seguintes mecanismos :

$\checkmark$ De primeiro grau são caracterizados os consórcios, as cadeias de fornecedores de grandes empresas, consórcios de marca e outras formas de cooperação entre as empresas;

De segundo grau as associações empresariais pró-ativas, cooperativas de crédito ou instituições de garantia de crédito. 
Revista Eletrônica de Ciência Administrativa (RECADM) - ISSN 1677-7387

Faculdade Cenecista de Campo Largo - Coordenação do Curso de Administração v. 3, n. 2, nov./2004 - http://revistas.facecla.com.br/index.php/recadm/

$\checkmark$ De terceiro grau aquelas formadas por todos os atores interessados no desenvolvimento da região (empresas, governos, bancos, universidades, etc.).

$\checkmark$ De quarto grau seria caracterizado por uma Agência de Desenvolvimento Regional, atuando através de um mecanismo operativo, como um Fórum de Desenvolvimento.

Hasenclever (2002,p.351) classifica três formas estilizadas de redes de empresas: 1) redes de subcontratação, nas quais se destaca a presença de uma empresa principal responsável pela coordenação dos fluxos internos à rede; 2) redes baseadas na aglomeração espacial de agentes em distritos industriais; 3) redes tecnológicas, montadas com o intuito de permitir um intercâmbio de competência a partir do qual seria possível viabilizar a introdução de inovação no mercado.

As aglomerações industriais têm tomado características não apenas da presença da empresa, mas também a um conjunto de outras instituições que conformam um ambiente local capaz de reforçar a competitividade empresarial, estimulando um processo de interação local que viabiliza o aumento da eficiência produtiva, criando um ambiente propício à elevação da competitividade dos agentes integrados ao arranjo.além de ser um fenômeno global capaz de transformar atividades empresariais, políticas e econômica para as regiões que sejam atrativas em relação aos negócios e empreendimentos.

Segundo, Hasenclever (2002,p.375) foram feitas análise que têm contribuído para um conhecimento maior e mais detalhado da presença de aglomerações industriais na economia brasileira. O autor sugere a partir dos dados levantados por Sabóia (2000) que mais de $15 \%$ do emprego são gerados a partir deste tipo de atividade e cita algumas tendências :

1. A formação de aglomerações industriais é mais nítida em determinados setores específicos;

2. Setores específicos ocorrem uma concentração em determinadas regiões como por exemplo, Calçados, (Rio grande do Sul).

3. Em determinados setores é comum à presença de aglomerações industriais concentrando mais de $60 \%$ do emprego industrial.

A exemplo do Nordeste do Brasil existem Distritos industriais em setores de alta tecnologia, podemos citar o Estado de Pernambuco como programa CESAR, e o Estado da Paraíba como pólo tecnológico de Campina Grande , juntamente com o apoio do parque tecnológico, O programa Poligene e o consórcio PBTECH. 
Revista Eletrônica de Ciência Administrativa (RECADM) - ISSN 1677-7387

Faculdade Cenecista de Campo Largo - Coordenação do Curso de Administração v. 3, n. 2, nov./2004 - http://revistas.facecla.com.br/index.php/recadm/

\section{3- MICRO E PEQUENAS EMPRESAS E REDES DE NEGÓCIOS}

As micros e pequenas empresas fazem parte da nova dinâmica do mercado, na sua evolução é a formação de redes de empresas que atuam de forma cooperada permitindo o crescimento de recursos e o aumento da capacidade de reação às inovações do mercado, seus sistemas logísticos aprimorados, sua experiência em grupo e o acesso a recursos financeiros.

Uma parcela significativa do PIB brasileiro é resultante de micros e pequenas empresas que estão diante de uma concorrência global, exigindo uma nova postura e estratégias de competição para alavancar novos mercados.

De acordo com o SEBRAE 2003, os micros e pequenas empresas, representam 98\% das empresas brasileiras, e destas 15.000 são exportadoras. Sobre as exportações apenas 600 delas é responsável por $80 \%$ de tudo o que é exportado, o que significa que a maioria das exportações nacionais está concentrada num grupo restrito de empresário.

Para atingir um mercado exportador é necessário ter qualidade, preço , capacidade e infra-estrutura para fornecer o produto no momento certo, de maneira correta a pessoa certa, três itens difíceis de conseguir pelo micro e pequeno empresário. O empresariado brasileiro precisa se voltar para uma cultura de comércio exterior. As micros e pequenas empresas reunidas através de redes de negócios, têm melhores oportunidades (coletividade das informações, a redução de custos e o conhecimento de novos mercados através da exportação) e maior potencial de sucesso.

Em estudo realizado por Zaleski (1999) na região de Emilia-Romagna no nordeste da Itália, identificou seu crescimento econômico baseado em redes flexíveis de pequenas empresas. A estrutura produtiva descentralizada da Emilia-Romagna começou a se formar a partir dos anos 60 quando os sindicatos passaram a pressionar as grandes empresas da região por melhores salários. Com um elevado índice de demissões, as pessoas passaram a montar seus próprios negócios, vendendo sua produção para as grandes fábricas, outras recorreram à terceirização de seus serviços como forma de reduzir o poder de pressão dos sindicatos. 
Revista Eletrônica de Ciência Administrativa (RECADM) - ISSN 1677-7387

Faculdade Cenecista de Campo Largo - Coordenação do Curso de Administração v. 3, n. 2, nov./2004 - http://revistas.facecla.com.br/index.php/recadm/

Com a recessão dos anos 70 e o crescimento do mercado por produtos especializados; os trabalhadores tornaram-se empreendedores a procura de um nicho de mercado. Essas pequenas empresas contavam com não mais que dois grandes compradores que ditavam os preços do mercado, de modo que os salários e os lucros eram baixos. (Zaleski, 1999).

Estas empresas utilizaram a estratégia de formar alianças para elaborarem projetos mais complexo , surgindo assim os consórcios que desenvolveram a região tornando-se um caso de sucesso de redes de empresas.

A estratégia é o meio pelo qual uma empresa reconhece suas necessidades básicas, desaprende parte do passado para poder descobrir o futuro, desenvolve capacidade de previsão do mercado de amanhã, cria metas que superam os limites e desafia os funcionários a conseguir, criativamente, a alavancagem dos recursos e desenvolve liderança em competências essenciais. Hamel e Prahalad (1995).

A união das micros e pequenas empresas em consórcio, oferece maiores vantagens em termos de flexibilidade de atendimento a pedidos diferenciados e assim agregam maior valor ao produto. Ao mesmo tempo ganha em escala em muitas das funções da cadeia produtiva conseguindo manter uma boa relação uma boa relação valor/preço, que lhes permite competir numa visão mais ampla que nas simples opções de liderança de custos ou diferenciação de produto.

A formação de redes de empresas tem por base estratégica a junção de esforços com o objetivo de produzir em escala maior e com elevada capacidade inovadora. Pequenas empresas normalmente são mais flexíveis e ágeis comparadas com as grandes empresas nas funções produtivas e isso possibilita uma viabilidade competitiva.

\section{4- CONSÓRCIO DE EXPORTAÇÃO}

A situação econômica atual do Brasil indica uma forte tendência do governo ao fomento e apoio às exportações. Este fato apresenta interesse e oportunidade para as empresas com capacidade de atender às exigências e necessidades do mercado internacional.

Para Porter (1999) os consórcios de exportação permitem as empresas locais concorrentes ou com produtos complementares, cooperar para levarem juntas um processo de exportação. O consórcio passa a ser a representação jurídica frente aos mercados 
Revista Eletrônica de Ciência Administrativa (RECADM) - ISSN 1677-7387

Faculdade Cenecista de Campo Largo - Coordenação do Curso de Administração v. 3, n. 2, nov./2004 - http://revistas.facecla.com.br/index.php/recadm/

internacionais, normalmente na forma de uma associação, obtendo importantes economias de escala.

Daemon (1993) define os consórcios de exportação como cooperativas com formas de concentração através da qual as empresas se unem mantendo as suas individualidades, possibilitando agregar uma oferta de maior dimensão, fazendo crescer o poder de negociação e aumentando a capacidade técnica e financeira. As cooperativas são utilizadas normalmente como formas de associação para o setor agrícola, enquanto os consórcios são direcionados para outros setores.

A Agência de Promoção à Exportação - APEX acredita que será através dos consórcios que um número maior de pequenos empresários irá ingressar no mercado externo, pois será através deles que o Governo poderá rapidamente aumentar a conscientização e a capacitação dos pequenos empresários para uma melhor atuação no mercado externo.

Os consórcios de exportação têm se mostrado de grande utilidade para pequenas empresas em diversos países, permitindo que, ao manter sua própria individualidade no mercado doméstico, exportem seus produtos para diferentes mercados, concorrendo com grandes fornecedores, beneficiando-se de sua eficiência operacional e de baixos custos de produção. (APEX, 1999).

Os resultados esperados na aplicação e implementação de consórcios de exportação são os que beneficiam diretamente as empresas, tais como a concretização de negócios, a realização de acordos de colaboração técnico-industrial com empresas do exterior, as melhorias do nível de design, qualidade, embalagem, processos produtivos, a redução de riscos e custos para cada uma das empresas e a incorporação de tecnologia.

A formação do consórcio não garante por si só a competitividade das empresas da região, mas sim, unido ao sistema econômico local com a participação de vários componentes como: universidades, governo, associações empresariais, cooperativas de crédito, além de outros elementos.

\subsection{A APEX- A Agência de Promoção à Exportação}

A função principal destes programas é apoiar as empresas de pequeno porte para que aumentem as suas exportações, elevem o número de empresas que vendem para o mercado externo e o número de produtos exportados. 
Revista Eletrônica de Ciência Administrativa (RECADM) - ISSN 1677-7387

Faculdade Cenecista de Campo Largo - Coordenação do Curso de Administração v. 3, n. 2, nov./2004 - http://revistas.facecla.com.br/index.php/recadm/

A APEX apóia algumas ações sempre em parceria com o setor privado e com os SEBRAEs estaduais. Entre estas ações estão a capacitação e treinamento de pessoal especializado em comércio exterior, pesquisas de mercado, rodadas de negócios, informação comercial e participação em feiras e seminários.

A formação dos consórcios proposta pela APEX é definida em três fases: primeiro o apoio à criação do consórcio, depois a constituição do consórcio e, por fim, sua manutenção. Na fase de apoio até a criação do consórcio, o objetivo principal é o de selecionar as empresas que formarão o consórcio, tendo como atividades a preparação da unidade gerencial do projeto, sensibilização e motivação das empresas, identificação das empresas e avaliação de suas experiências de exportação e de seu estágio tecnológico.

São levados em consideração o porte e a experiência de cada empresa, identificando a estrutura e forma de organização do consórcio mais adequada para o grupo de empresas selecionadas.

A segunda fase é a constituição do consórcio em si, uma etapa de curta duração, que tem por objetivo a instalação do consórcio, com ênfase nas ações administrativas e jurídicas, definindo o estatuto, elaborando os regimentos internos, delineando o perfil do gerente e a constituição jurídica do consórcio.

Por fim, na fase de manutenção, o objetivo é de consolidar e fortalecer os consórcios constituídos, com o foco em ações de melhoria da oferta exportável e em atividades de promoção à exportação. O custeio das atividades de gestão, contratação do gerente, locação de escritório, despesas de comunicação, estudos de mercado, avaliação da necessidade de contratar consultorias de marketing, design, qualidade, produção e ações direcionadas à melhoria da oferta exportável, são algumas das atividades desenvolvidas nesta etapa.

As empresas participantes deverão definir se os produtos serão exportados com marca comum do consórcio ou com marca própria, acompanhada ou não por um selo do consórcio de qualidade estipulado conjuntamente.

De acordo com a APEX, os consórcios de exportação podem ser caracterizados como uma associação entre empresas independentes, de pequeno ou médio porte, com o objetivo de desenvolver em conjunto suas atividades de exportação, seja para um produto ou para uma cadeia produtiva.

Através de consórcios, as empresas podem alavancar vantagens competitivas, através da compra direta dos fabricantes; da gestão da exportação; das facilidades na 
Revista Eletrônica de Ciência Administrativa (RECADM) - ISSN 1677-7387

Faculdade Cenecista de Campo Largo - Coordenação do Curso de Administração v. 3, n. 2, nov./2004 - http://revistas.facecla.com.br/index.php/recadm/

formação de parcerias; na penetração em novos mercados; na redução do risco através da diversificação do negócio; do acúmulo de know-how em marketing internacional; no fortalecimento de seu produto na indústria como também no aumento do acesso às informações técnica.

\section{5- O PARQUE TECNOLÓGICO E A FORMAÇÃO DE CONSÓRCIO DE EXPORTAÇÃO : A EXPERIÊNCIA DO CONSÓRCIO DE SOFTWARE DA PARAÍBA - PBTECH}

Os parques tecnológicos são estruturas de redes de empresas, direcionadas especificamente para setores de alta tecnologia. Estes compreendem a integração numa mesma região, de componentes, softwares e serviços necessários à obtenção de produtos de alta tecnologia, como computadores, sistemas eletrônicos etc. Normalmente os parques tecnológicos estão localizados em regiões onde se dispõe de infra-estrutura e base de conhecimento cientifico e tecnológico, como centros de pesquisas, universidades.

Estes, por sua vez, absorvem a mão-de-obra qualificada que permite a intensificação de processo de aprendizado entre os seus membros, e muitas empresas são originárias do próprio campo universitário.

O pólo de tecnologia de Campina Grande nasceu com o crescimento da tecnologia desenvolvida pela Universidade Federal da Paraíba - Campus II que desde em 1967 investe na informática. Em 1984 houve a criação do parque tecnológico. Atualmente o setor movimenta cerca de 500 empregos diretos, com uma massa salarial de R\$ 470 mil mensais. As empresas fabricam softwares, hardwares, aplicativos, sistemas de segurança e automação comercial.

O programa de apoio ao empreendimento é composto de quatro fases básicas: iniciação, preparação, pré-incubação e estágio avançado - incubação. As empresas num estágio avançado podem seguir um caminho natural que é a incubação da empresa no Parque Tecnológico na Incubadora Tecnológica de Campina Grande.

O Consórcio de Exportação de Software PBTECH, foi criado em dezembro de 2002 com o objetivo de promover o desenvolvimento do mercado de software paraibano, está reunindo 9empresas de Campina Grande e uma de João Pessoa que juntas pretendem intensificar o processo de divulgação, comercialização local e nacional, além da exportação dos produtos fabricados no Estado. 
Revista Eletrônica de Ciência Administrativa (RECADM) - ISSN 1677-7387

Faculdade Cenecista de Campo Largo - Coordenação do Curso de Administração v. 3, n. 2, nov./2004 - http://revistas.facecla.com.br/index.php/recadm/

Para os empresários do segmento, através do consórcio PBTECH será possível aumentar o volume de recursos destinados ao setor de software, além de agregar novas empresas no mercado de exportação. O Consórcio é financiado pelo Sebrae e Agência de Promoção de Exportações (Apex), cujo foco principal são as micros e pequenas empresas de base tecnológica.

As empresas que formam o Consórcio são a Light Infocon, Insiel, Apel, Decisão, Era Digital, S. Toledo, Zênite, Trade Software, CG Sistemas e Aptools. Das empresas inseridas no PBTECH, três já estão consolidadas no mercado de exportação. A Apel está há anos no mercado internacional, produzindo sonorização eletrônica para metrô.

Ampliar o mercado externo para os produtos "made in Paraíba" e aumentar o volume de negócios no Brasil, são os principais objetivos do Consórcio formado por empresas da área de base tecnológica, utilizando como ferramenta estratégica da Internet.

Para abrir o mercado externo ao software produzido na Paraíba a estratégia do consórcio PBTECH é viabilizar a participação de empresas paraibanas em feiras e outros eventos como também comercializar os produtos e serviços através da tecnologia da Internet. Em um importante evento realizado no mês de março de 2003, na Alemanha, das 21 empresas brasileiras que compareceram ao evento cinco foi do Estado da Paraíba.

Com 64 empresas de tecnologia da informação, que faturam em torno de R\$ 27 milhões por ano, o setor de tecnologia cresce a cada ano na cidade e alguns dos fatores que podem explicar o surgimento de novos empreendimentos na área, são as qualidades dos profissionais, o incentivo à cultura de redes de empresa, na cooperação da Universidade e centro de pesquisas como também a existência de ambientes como o Poligene e o Parque Tecnológico com o apoio institucional, técnico e financeiro, para a transformação das idéias de jovens empreendedores em negócios de sucesso como softwares.

O sucesso e expansão dos negócios estão começando a se tornar realidade com o desenvolvimento de um software chamado Conferência Web, que trata-se de um ambiente virtual para a realização de entrevistas coletivas ou reuniões on-line. Um dos diferenciais desta tecnologia está na gravação do conteúdo gerado pelos participantes. Esta tecnologia está sendo bem aceita no mercado e a tendência é crescer.

Campina Grande segundo a revista americana NewsWeek, está entre as noves maiores cidades tecnológicas do mundo, atraindo para o seu pólo tecnológico empresas multinacionais. A referência do pólo tecnológico de Campina Grande se reflete nas empresas multinacionais que estão se instalando ou firmando parcerias na cidade. Northel, 
Revista Eletrônica de Ciência Administrativa (RECADM) - ISSN 1677-7387

Faculdade Cenecista de Campo Largo - Coordenação do Curso de Administração v. 3, n. 2, nov./2004 - http://revistas.facecla.com.br/index.php/recadm/

HP e Motorola são algumas destas empresas. Atualmente são oito empresas incubadas, além de outras que são associadas ou virtuais, que contam com um ambiente de infraestrutura compartilhada.

\section{6- METODOLOGIA}

Este trabalho adotou o estudo descritivo de caráter exploratório. O estudo exploratório emerge para elaborar explicações de determinados fenômenos. Para Sâmara \& Barros (1994,p.19), os estudos exploratórios tem como principal característica à informalidade, a flexibilidade e a criatividade, e neles procura-se obter um primeiro contato com a situação a ser pesquisada ou melhor conhecimento sobre o objeto em estudo levantado em um projeto de pesquisa. O estudo exploratório pode ser essencial como primeiro passo para determinar uma situação de mercado a partir da obtenção de informações.

A coleta de dados foi realizada em três empresas que fazem parte do Consórcio de PBTECH situadas na cidade de Campina Grande , estado da Paraíba. Por pedido das empresas, o estudo não publicou o nome de fantasia e a razão social das mesmas aqui consideradas como empresas $\mathrm{X}, \mathrm{Y}$ e Z $\mathrm{Z}$ O instrumento de coleta de dados foi realizado através de entrevista pessoal e questionário estruturados, com perguntas abertas e fechadas.

As variáveis utilizadas foram: Tempo de permanência no mercado; Razão que levou a empresa a entrar no consórcio; expectativas, desenvolvimento regional, competitividade; inovações tecnológicas; aumento do conhecimento empresarial com relação aos processos produtivos, custos.

Com relação às técnicas estatísticas foi utilizado um conjunto de valores baseados na escala de Likert, de acordo com ordem de concordância , usando de 1 a 5 sendo, 1discordo, 2-discordo parcialmente, 3-nem discordo, nem concordo, 4- concordo parcialmente , 5- concordo.

\section{7- ANÁLISE DOS RESULTADOS}




\section{Revista Eletrônica de Ciência Administrativa (RECADM) - ISSN 1677-7387 \\ Faculdade Cenecista de Campo Largo - Coordenação do Curso de Administração v. 3, n. 2, nov./2004 - http://revistas.facecla.com.br/index.php/recadm/}

A partir da analise dos resultados da pesquisa, fundamentada na bibliografia de Hasenclever (2002), pode-se afirmar que este estudo se caracteriza por redes de distritos e aglomerações industriais, tendo em vista que a noção de distritos industriais tem sido correlacionada não apenas por presença de empresas, mas também a um conjunto de outras instituições que conformam um ambiente local capaz de reforçar a competitividade das empresas atuantes nesses distritos, como por exemplo distritos industriais em setores de alta tecnologia, o caso dos Parques Tecnológicos.

Procurou-se identificar os pontos principais na visão das empresas sobre a vantagem de entrar numa rede de empresas e o que a mesma espera em termos de resultados futuros.

Empresa X - Atua no mercado há mais de 20 anos, desenvolve produtos eletrônicos, tem aproximadamente 48 funcionários e não busca uma produção de escala. Sua meta é atingir o Mercosul e a América.

O indicador de maior importância que a levou a entrar numa rede de empresa de softwares foi à ampliação do mercado de seus produtos e serviços. Constatou-se também que a redução de custos e riscos para cada um dos participantes do projeto ; a formação de um grupo de empresários e multiplicadores para disseminação as outras tecnologias e a mudança de atitude frente à internacionalização são instrumentos considerados importantes para a empresa está inserida no consórcio.

Um ponto importante para o desenvolvimento regional na visão da empresa X é o desenvolvimento da cultura exportadora como também o favorecimento das possibilidades de colaboração industrial e comercial entre empresas paraibanas e empresas do exterior. Um outro aspecto considerado importante para a empresa é a sensibilização do segmento às tendências da tecnologia. Por outro lado à superação da tendência da individualidade, melhoramento do conhecimento das empresas com relação processos produtivos, técnicas de comercialização e valor agregado do produto foram considerados aspectos não muito importante.

Os resultados esperados pela empresa com relação ao consórcio são: primeiramente a concretização de negócios e a realização de acordos de colaboração técnico-industrial; o incremento no nível de inovações tecnológicas , dos design, da qualidade, da embalagem, dos processos produtivos e a redução de riscos e custos para cada uma das empresas. No 
Revista Eletrônica de Ciência Administrativa (RECADM) - ISSN 1677-7387

Faculdade Cenecista de Campo Largo - Coordenação do Curso de Administração v. 3, n. 2, nov./2004 - http://revistas.facecla.com.br/index.php/recadm/

entanto a incorporação de tecnologia não representou valor significativo para a empresa como estratégia de desenvolvimento.

Empresa Y -Atua no mercado há mais de 20 anos na área de desenvolvimento de softwares . Com investimentos privados, e financiamentos da FINEP-MCT, do CNPq, Programa SoftEx, BNDES e PERNAMBUCO S/A, a empresa busca manter-se sempre na vanguarda do desenvolvimento tecnológico, inclusive com parcerias internacionais.

O que incentivou a empresa a entrar no consórcio de exportação foi a ampliação do mercado; a possibilidade de redução de custos e riscos para cada um dos participantes do projeto ; a formação de um grupo de empresários e multiplicadores para disseminação as outras tecnologias considerados fatores importantes para a empresa está inserida no consórcio.

Outros aspectos considerado importante para a empresa são: o desenvolvimento regional; o desenvolvimento da cultura exportadora como também o favorecimento das possibilidades de colaboração industrial e comercial entre empresas paraibanas e empresas do exterior.

Os resultados esperados pela empresa com relação ao consórcio são: primeiramente a concretização de negócios e a realização de acordos de colaboração técnico-industrial; o incremento no nível de inovações tecnológicas, o design, a qualidade, a embalagem, os processos produtivos e a redução de riscos e custos para cada uma das empresas.

A Empresa $\mathbf{Z}$ atua no mercado há mais de 25 anos, no desenvolvimento e industrialização produtos na área de eletro-eletrônica, absorvendo a tecnologia oriunda dos centros de pesquisa eletro-eletrônica da Universidade Federal da Paraíba.

Os motivos que levaram a empresa a entrar no consórcio foram a redução de custos, o desenvolvimento de uma cultura exportadora, a sensibilização às tendências da tecnologia; o favorecimento das possibilidades de colaboração industrial e comercial entre empresas paraibanas e empresas do exterior; a mudança de atitude frente à internacionalização; a formação de um grupo de empresários e multiplicadores para disseminação a outras tecnologias, por outro lado a empresa discorda parcialmente do aspecto relacionado ao melhoramento do conhecimento das empresas com relação ao processos produtivos, técnicas de comercialização, valor agregado ao produto, como também a superação da tendência da individualidade 
Revista Eletrônica de Ciência Administrativa (RECADM) - ISSN 1677-7387

Faculdade Cenecista de Campo Largo - Coordenação do Curso de Administração v. 3, n. 2, nov./2004 - http://revistas.facecla.com.br/index.php/recadm/

\section{8- CONSIDERAÇÕES FINAIS}

As micros e pequenas empresas de base tecnológica tem fortalecido o desenvolvimento regional através da formação de redes de empresas. Especificamente na no Estado da Paraíba estas empresas estão procurando superar as dificuldades oriundas do mercado globalizado através do consórcio PBTECH, obtendo acesso às informações, acesso a crédito e tecnologia, reduzindo seus custos com fornecedores, adquirindo promoção de seus produtos e aumentando sua competitividade no mercado exterior.

Neste momento não só o Estado da Paraíba mais o Brasil está procurando aumentar suas exportações e incentivando a participação das micros e pequenas empresas neste mercado, acredita-se ser o momento ideal para a formação de consórcios de exportação.

Podemos concluir que de acordo com a literatura e o conceito Hasenclever at al (2002,p.376) este estudo se caracteriza por redes de distritos e aglomerações industriais, tendo em vista que a noção de distritos industriais tem sido correlacionada não apenas por presença de empresas, mas também a um conjunto de outras instituições que conformam um ambiente local capaz de reforçar a competitividade das empresas atuantes nesses distritos, como por exemplo distritos industriais em setores de alta tecnologia, o caso dos Parques Tecnológicos.

O caso do pólo tecnológico de Campina Grande no que se refere à utilização das estratégias de consórcio de exportação apresenta uma vantagem competitiva, por existir empresas de base tecnológica como núcleo central da rede, e uma forte tendência de crescimento a partir da capacitação tecnológica preexistente na cidade.

Um outro fator que favorece o desenvolvimento regional é a aglomeração de empresas de base tecnológica que atuam com o suporte na tecnologia da Internet , e o incentivo de outras instituições que conformam o ambiente local capaz de reforçar a competitividade das empresas como por exemplo a Universidade Federal de Campina Grande , o Parque Tecnológico, o programa Poligene, SEBRAE e APEX que apresentam um efetivo resultado para o desenvolvimento regional.

Através da pesquisa realizada junto às empresas, pode-se afirmar que a maioria são oriunda do mercado tradicional e estão no mercado a mais de vinte anos, isto significa que são empresas já consolidadas na região e que procura através do consórcio a ampliação do mercado exterior. 
Revista Eletrônica de Ciência Administrativa (RECADM) - ISSN 1677-7387

Faculdade Cenecista de Campo Largo - Coordenação do Curso de Administração v. 3, n. 2, nov./2004 - http://revistas.facecla.com.br/index.php/recadm/

Os motivos levaram estas empresas formar uma rede de empresas consorciadas é a redução de custos e riscos para cada um dos participantes do projeto; a formação de um grupo de empresários e multiplicadores para disseminação as outras tecnologias e a mudança de atitude frente à internacionalização.

As empresas esperam que o consórcio concretize seus negócios no mercado exterior, realize acordos de colaboração técnico-industrial, como também reduza os custos e os riscos de negócios. No entanto a incorporação de tecnologia não representou valor significativo para as empresas como estratégia de desenvolvimento.

Portanto pode-se concluir que a formação de rede de empresas de consórcios vem se tornando uma estratégia competitiva para as micro e pequenas empresa de base tecnológica que buscam uma cultura de trabalhar em rede. A integração das redes de empresas deixou de ser uma função meio, para ser uma função fim, por necessidade de manter-se competitiva no mercado global.

\section{9- REFERÊNCIAS}

1. CÂNDIDO, Gesinaldo, ABREU, Aline. Os Conceitos de Redes e as Relações interorganizacionais : um estudo exploratório. Anais ENAMPAD 2000 / CDROM. Florianópolis, 2000.

2. CASAROTTO Filho, Nelson. Redes de pequenas e médias empresas e desenvolvimento local: estratégias para a conquista da competitividade global com base na experiência italiana. São Paulo : Atlas, 1998.

3. CASTELLS, Manuel. A sociedade em rede. A era da informação, economia, sociedade e cultura. 4. ed. São Paulo: Impresso Brasil, 2000.

4. DAEMON, Dalton. Empresas de comércio internacional : organização e operacionalidade. Blumenau : Ed. Da Furb, 1993.

5. HAMEL, Gary, PRAHALAD, C. K. Competindo pelo futuro: estratégias inovadoras para obter o controle do seu setor e criar os mercados de amanhã. Rio de Janeiro: Campus, 1995.

6. HANSECLEVER, Lia; KUPLER David. Economia Industrial - Fundamentos Teóricos e Práticas no Brasil. Rio de Janeiro. Campus. 2002. 
Revista Eletrônica de Ciência Administrativa (RECADM) - ISSN 1677-7387 Faculdade Cenecista de Campo Largo - Coordenação do Curso de Administração v. 3, n. 2, nov./2004 - http://revistas.facecla.com.br/index.php/recadm/

7. PORTER, Michael. Competição = On Competition : estratégias competitivas essenciais. Tradução de Afonso Celso da Cunha Serra. Rio de Janeiro : Campus, 1999.

8. SAMARA, Beatriz Santos; BARROS, José. Pesquisa de marketing: conceitos e metodologia. 2.ed. São Paulo: Makron Books, 1994.

9. ZALESKI, Neto, J. - Formação de redes flexíveis no contexto do progresso regional, Tese de doutoramento, Florianópolis, EPS/UFSC, 1999.

10. APEX. Disponível na Internet no endereço http://www.apex.sebrae.br. Consulta realizada em julho de 1999.

11. Consórcio Paraíba PBTECH. Disponível na Internet . Endereço www.softech.com.br, 2003.

12. Parque Tecnológico de Campina Grande. Disponível na Internet. Endereço www.paqtc.rpp.br, 2003. 